\title{
Agentic, communal, and spiritual traits are related to the semantic representation of written narratives of positive and negative life events
}

\author{
Danilo Garcia ${ }^{1,2,3,4^{*}}$, Henrik Anckarsäter ${ }^{4}$, Oscar N. E. Kjell ${ }^{1,5}$, Trevor Archer ${ }^{1,6}$, Patricia Rosenberg ${ }^{1}$, \\ C. Robert Cloninger ${ }^{3}$ and Sverker Sikström ${ }^{1,5^{*}}$
}

\author{
*Correspondence: \\ danilo.garcia@icloud.com; \\ danilo.garcia@neuro.gu.se \\ sverker.sikstrom@psy.lu.se \\ ${ }^{1}$ Network for Empowerment \\ and Well-Being, Gothenburg \\ and Lund, Sweden \\ ${ }^{5}$ Department of Psychology, \\ Lund University, Lund, \\ Sweden \\ Full list of author information \\ is available at the end of the \\ article
}

\begin{abstract}
Background: We used a computational method to quantitatively investigate the relationship between personality and written narratives of life events. Agentic (i.e., selfdirectedness), communal (i.e., cooperativeness), and spiritual (self-transcendence) traits were of special interest because they represent individual differences in intentional values and goals, in contrast to temperament traits, which describe individual differences in automatic responses to emotional stimuli. We also investigated which pronouns were most common in relation to personality constructs that were significantly related to the narratives.
\end{abstract}

Methods: Personality was assessed among 79 adolescents at one point in time using the NEO Personality Inventory-Revised (NEO-PI-R) and the temperament and character inventory $(\mathrm{TCl})$. Six months later, adolescents were asked to write down the most positive or the most negative event that had happened to them in the last 3 months. Adolescents were explicitly instructed to answer the following questions within their narratives: What happened? Who were involved? Why do you think it happened? How did you feel when it happened? How do you think the involved persons felt? The descriptions were quantified using a computational method in which the latent semantic analysis algorithm generates a semantic representation of the narratives.

Results: Only self-directedness, cooperativeness, and self-transcendence were related to the semantic representation of the narratives. Moreover, cooperativeness and selftranscendence were associated with less frequent usage of singular pronouns (e.g., me respectively mine).

Conclusions: Agentic, communal, and spiritual traits are involved when adolescents describe positive and negative life experiences. Moreover, high levels of communal and spiritual traits are related to less self-focused narratives.

Keywords: Agency, Big five, Communion, Latent semantic analysis, Life story, Semantic spaces, Pronouns, Temperament and character inventory

\section{Springer}

๑) 2015 Garcia et al. This article is distributed under the terms of the Creative Commons Attribution 4.0 International License (http:// creativecommons.org/licenses/by/4.0/), which permits unrestricted use, distribution, and reproduction in any medium, provided you give appropriate credit to the original author(s) and the source, provide a link to the Creative Commons license, and indicate if changes were made. 


\section{Background}

The notion of a narrative self emphasizes the storied nature of human behavior (Cohler 1982; McAdams 1993, 2001). Research on life narratives suggests that in late adolescence and young adulthood, humans "begin to reconstruct the personal past, perceive the present, and anticipate the future in terms of an internalized and evolving self-story, an integrative narrative of self that provides modern life with some modicum of psychosocial unity and purpose" (McAdams 2001, p. 101). Adolescence is indeed an important phase in the development of an individual's goals and values that organize a person's lifestyle in relation to the self, others, and something greater than the self (i.e., character or self-concept; Erikson 1968; Magen 1998). Importantly, in this period of life, adolescents perceive daily problems (e.g., coping with a minor social conflict) to be equally stressful as major life events (e.g., parent being remarried) (McCullough et al. 2000). In this framework, adolescents' initial interpretations of events are part of the life narrative (Wilson 2011); thus, adolescents' conversations about recent life events (e.g., Weeks and Pasupathi 2010), self-event connections (Pasupathi et al. 2007), and traumatic events (Daiute 2010) provide knowledge about both their subjective experience and their selfconcept or character (Magen 1998; Garcia and Sikström 2013).

As humans, we have the ability and urge to find explanations and meaning in life events, probably constructing our interpretations on our own degree of agency (i.e., autonomy and the fulfillment and enhancement of the self) and communion (i.e., engagement in the protection and relations to others) (McAdams 2001; Gazzaniga 2011). For instance, adults who perceive themselves as autonomous or self-directed describe negative life events as good recollections focusing on how they managed to cope with the event, which in turn, makes the memory of that specific event a meaningful life experience. This contributes to build up resilience for future stressful events and both mirrors and strengthens individuals' self-concept as autonomous and resourceful beings (see McAdams 2001; McAdams et al. 2004; McLean and Fournier 2008; Lilgendahl and McAdams 2011). Indeed, agentic and communal personality traits are empirically related to well-being, happiness, and health-healthy and happy individuals are autonomic, resourceful, self-directed, and have the capacity for helpful cooperation (Cloninger 2013; Nima et al. 2013; Schütz et al. 2013). Regarding adolescents, research shows that adolescents' conversations about recent emotional events with parents and friends seem to be saturated with issues of agency (Weeks and Pasupathi 2010). Moreover, adolescents' ability to feel trust and responsibility at a social level (i.e., communion) predicts less use of cigarettes, alcohol, marijuana, and other types of drugs (Wray-Lake et al. 2012). In addition to agentic and communal traits, research from at least three different fields, cultural (e.g., Shweder et al. 1997) developmental (e.g., Magen 1996) and personality psychology (e.g., Cloninger 2004, 2006, 2013), suggest that humans also find meaning in life events and harmony in life through their ability to find an interconnection with all life and appreciation of the whole world around us (i.e., transcendence of the self or spirituality). In sum, besides being associated to adolescents' well-being (e.g., Cloninger and Zohar 2011; Garcia 2011, 2012a; Garcia et al. 2013a, c; Nima et al. 2012, 2013; Nima and Garcia 2015; Schütz et al. 2013a; Magen 1996), agentic, communal, and spiritual personality traits can be expected to be associated to the narratives of their everyday experiences. 
Individuals' apprehension of life events as an expression of individual differences is commonly accepted (Sandelowski 1991; Gazzaniga 2011) and is usually approached using fairly rigorous experimental human coding procedures (Chung and Pennebaker 2007). Over the last decade, Pennebaker and colleagues (for a review see Pennebaker 2011) have innovated text analysis through their program called Linguistic Inquiry and Word Count, or LIWC (Pennebaker et al. 2001). Basically, LIWC computes the percentage of total words in specific linguistic categories (e.g., standard function word categories: first, second, and third person pronouns, articles, prepositions), which enables the investigation of how these might vary in relation to other outcomes such as changes in health measures. The study of writing about emotional events has demonstrated that, although almost without meaning by their own, the way people use 'function words' such as pronouns (e.g., I, we, you, they) is significantly related to mental and physical health, as well as other important outcomes such as academic success. For instance, first person pronouns (e.g., I) are most common among depressed individuals (Campbell and Pennebaker 2003; Pennebaker 1997, 2011). With regard to personality, Extraversion, which is regarded as both an agentic and communal personality trait, has been found to be related to a tendency to make distinctions through the use of inclusive words, such as "and" and "with" (Pennebaker and King 1999). Thus, this linguistic style analysis at the micro-level is powerful, valid, and useful for the analysis of narratives in relation to personality traits (cf. Gustafsson Sandén et al. 2014a, b; Gustafsson Sandén et al. 2015).

In addition, using a macro-level of analysis some researchers have found that extroverts tell stories about romance more so than introverts, whose stories were more often concerned with family, hometown, and past events (Thorne et al. 2006). There is indeed a large and important line of research linking thematic narrative content with the Big Five traits (e.g., Dunlop and Tracy 2013; Lodi-Smith et al. 2009; McLean et al. 2007). For example, Neuroticism is positively associated with an emotionally negative narrative tone, agreeableness is associated to communal themes (e.g., friendship, caring for others) (McAdams et al. 2004). Nevertheless, McAdams (2001) has suggested that the Big Five model might be limited to temperament traits that "are global, stable, linear and comparative dimensions of human individuality" (p. 111; see also Haidt 2006). In contrast to temperament traits, which describe individual differences in automatic responses to emotional stimuli, character traits represent individual differences in intentional values and goals in relation to the self, others, and something bigger than the self. For instance, contrary to expectations Conscientiousness is not associated with themes of agency and Extraversion is unrelated to positive narrative tone (McAdams et al. 2004). Also in this line, there are indications that the Big Five traits do not have a major impact on how individuals interpret events in their lives (Luhmann et al. 2014). Hence, temperament does neither reflect nor explains all aspects of human personality, such as, the narrative self.

Cloninger's psychobiological model of personality (Cloninger et al. 1993) is based on findings from neuroanatomy and neurophysiology as well as developmental and clinical psychology and psychiatry. Differences in the major brain systems for procedural versus propositional learning lead to the distinction between four temperament and three character traits (for a review see Cloninger 2004). The four temperament dimensions are defined in terms of individual differences in behavioral learning mechanisms, 
explaining responses to signals of punishment or non-reward (harm avoidance), novelty and signals of reward or relief of punishment (novelty seeking), maintained response to socially rewarded behavior (reward dependence), and resistance to extinction of previously rewarded behavior (persistence). In contrast, character involves individual differences in self-concepts about goals and values and voluntary choices in life (Cloninger $2004,2006,2013)$. Character is the self-organization of an individual's thoughts in three dimensions: self-directedness (based on the concept of the self as an autonomous individual), cooperativeness (based on the concept of the self as an integral part of humanity or society), and self-transcendence (based on the concept of the self as an integral part of the whole universe). Cloninger et al. (1993) has developed the temperament and character inventory (TCI) to measure these personality dimensions. The TCI has been widely used in the investigation of personality's neurobiological foundations, together with other research technologies, such as, molecular neuroimaging (Borg et al. 2003), structural neuroimaging (Yamasue et al. 2008), and genetics. In addition, the TCI has been translated into and validated in several languages, such as, Swedish (Brändström et al. 1998), Dutch (De la Rie et al. 1998), Japanese (Kijima et al. 2000), Turkish (Köse et al. 2002), and Spanish (Gutierrez and Torrens 2001; Garcia et al. 2013a, b, c). These studies show sound psychometric properties comparable to what was found for the original American English version. What is more, there is TCI normative data in 22 countries (e.g., USA, Sweden, Japan, China, Mexico, Italy) on four continents (North and South America, Europe, Asia, Oceania) showing that the factor structure is identical around the world and also data on age appropriate norms showing that the same dimensions are present across the lifespan as well (C. R. Cloninger, personal communication, June 10, 2015; see also Josefsson et al. 2013). The TCI is sensitive to reading level, but for a forthcoming adolescent and adult short version, there was no need to change wording (C. R. Cloninger, personal communication, June 10, 2015; see also the non-significant association between TCI dimensions and cognitive ability among adolescent twins in Mousavi et al. 2015). Hence, suggesting that the TCI can be used among adolescents to measure agentic, communal, and spiritual traits. To the best of our knowledge, however, no other study has investigated narratives of life events in relation to Cloninger's model of personality.

\section{The present study}

As an addition to past research at the micro- (e.g., word analysis) and macro-level (e.g., theme analysis), we use a computational method for quantifying semantic content of words in order to investigate if personality traits, using both the Big Five and Cloninger's model, are related to written narratives of life events. This method is based on the latent semantic analysis algorithm, which stems from computational linguistics where a high dimensional semantic representation of words can be generated from co-occurrence of words in massively large text corpora. In theory, the context in which words are typically present has a meaning that is similar to the meaning of the words in that specific context (Landauer and Dumais 1997; Landauer 2008; Landauer et al. 2008). Applied to a text corpus, it produces a highly multi-dimensional semantic space, in which each word or narrative is represented as a vector in this space. The basic idea is that co-occurrences of words produce information about the semantic meaning of the words/narrative. 
The quantification of the adolescents' narratives allowed us to use standard statistical tests to investigate if self-reported psychometric measures of personality are significantly related to the semantic representation of the written narratives of positive and negative life events (for a detailed description of using and applying semantic analysis see Arvidsson et al. 2011; Garcia and Sikström 2013, 2014; Garcia et al. 2015; Rosenberg et al. 2013). As suggested by macro-level of analysis showing that narratives comprise agentic and communal themes, we expected that the semantic representation of the written memories of life events would be significantly related to agentic (i.e., selfdirectedness) and communal (i.e., cooperativeness) traits. No relationships between narratives and temperament traits were expected, including the traits measured by the Big Five Model. This is because retrospective reports of emotions (Scollon et al. 2009) and the recollection of emotional events (Cloninger and Garcia 2015) are expected to be influenced by the individuals' values and goals (i.e., character), rather than being strongly related to actual emotions derived from the experience (i.e., temperament).

Moreover, the study of expressing emotions through written words (i.e., micro-level analysis) has demonstrated that, although almost without meaning by their own, the way people use 'function words' such as pronouns (e.g., I, we, you, they) is significantly related to mental and physical health, as well as other important outcomes such as academic success. For example, first person pronouns (e.g., I) are most common among depressed individuals (Campbell and Pennebaker 2003; Pennebaker 1997, 2011). Hence, this suggests that the usage of first person pronouns in narratives of life events should be negatively correlated with an individual's agentic (i.e., self-directedness), communal (i.e., cooperativeness), and spiritual traits (i.e., self-transcendence).

\section{Method}

Measures

The Big Five Model of personality The NEO Personality Inventory-Revised (NEO-PI-R; Costa and McCrae's 1992) was used to assess personality according to the five-factor model. The NEO-PI-R measures the five lexical generated traits: neuroticism, extraversion, agreeableness, consciousness, and openness (240 items with a 5-point Likert scale: $1=$ strongly disagree to $5=$ strongly agree). In the present study Cronbach's $\alpha$ varied between 0.84 and 0.92 among traits.

Cloninger's Psychobiological Model of personality The temperament and character inventory (TCI; Cloninger et al. 1993) was used to measure the four temperament and three character dimensions of the psychobiological model of personality (238-items with forced binary answer: yes or no; Cloninger et al. 1993). The four temperament dimensions are: novelty seeking, harm avoidance, reward dependence, and persistence. The three character dimensions are: self-directedness, cooperativeness, and self-transcendence. In the present study Cronbach's $\alpha$ varied between 0.75 and 0.90 among dimensions.

Description of a life event The affect, intentionality, effort and adaptation to a life event measure (Garcia 2012b; Garcia and Sikström 2013) was used to ask participants to recollect and then write down at random either the most positive or the most negative event in their life during the last 3 months (see Suh et al. 1996, who show that only writing about life events within the last 3 months influence happiness and well-being significantly). In the positive condition, participants are specifically asked to describe the 
most positive event during the last 3 months that to the greatest degree has enhanced their happiness. In contrast, in the negative condition, participants are asked for the most negative event in their life during the last 3 months that to the greatest degree had decreased their happiness. Both conditions instruct participants to answer the following questions when describing the event: What happened? Who were involved? Why do you think it happened? How did you feel when it happened? How do you think the involved persons felt?

\section{Participants and procedure}

Pupils at a high school in the south of Sweden participated in the study. The whole population $(\mathrm{N}=90)$ was contacted (see Garcia and Sikström 2013 in which part of this data was previously analyzed). Due to sickness 11 adolescents did not participate in at least one part of the study. The final sample was composed of 21 boys and 58 girls with a mean age of 16.65 years $(S D=0.95$, range 15-18). There is evidence that adolescents have reduced reliability for the personality instruments used here, especially for those below 17 years of age; a cohort that made about $51 \%$ of the sample studied here (e.g., Brändström et al. 2008; De Fruyt et al. 2000a; Moreira et al. 2012). Although never tested, this drop in reliability is often attributed to lower reading or comprehension ability among adolescents below 17 years of age. The Cronbach's alphas, however, were acceptable for both instruments and in the whole sample in the present study (see Additional file 1: Table S1 for reliability analysis on the personality traits for different age groups).

The adolescents in the present study had consent from their teachers and parents to participate. At a parent meeting, all parents and teachers were informed of the present and other studies being conducted among adolescents at the school. The nature of the studies was explained (e.g., instruments, confidentiality, participation being voluntary) and questions were addressed at the same meeting. Pupils were told that their involvement was voluntary and that the study was divided in three parts. The first (T1) and second part (T2) were one week apart and the third part of the study (T3) was conducted 6 months later. The pupils were told that the study involved how high school pupils think about their lives in different situations. All adolescents received cinema tickets at each part of the study for their participation. To ensure confidentiality and to enable matching of answers from each part, participants were asked to write the last four digits of their social security number. The study was conducted in the pupils' classrooms during school hours. Each group contained $20-30$ pupils. At T1, all participants were presented, at random, with either the Big Five or the TCI measure. At T2, the participants received the other measure of personality. This procedure enabled us to ensure that the participants completed the whole battery of personality measures without becoming too tired. At T3, 6 months later, participants were randomly assigned to one of the two conditions: describe the most positive $(n=40 ; 50.63 \%)$ or the most negative life event $(n=39 ; 49.37 \%)$ that had happened to them in the last 3 months. An associate who was blind to the hypothesis transcribed these descriptions.

\section{Data analysis}

Creation of a semantic representation The latent semantic analysis algorithm (Landauer et al. 2008) was used to create a semantic representation of the words participants 
generated. Simply put, the quantified semantic representation of the generated words is created from data consisting of frequencies of co-occurrences of the words using a large amount of text that is fairly representative of all the words in natural language. Perhaps the most important factor for creating a semantic representation is the size of the corpus used, where a larger text corpus generates a semantic space with a higher quality. Thus, to achieve a high quality representation it is highly recommended to create the semantic representation on a corpus that is as large as possible, and then apply this representation on the to-be-analyzed data set (in this case the narratives generated by the participants), which typically is relatively small. In essence, the relatively small number of words in the narratives generated by participants is mapped to a semantic representation (called a semantic space) constructed from a very large quantified text corpus. The method for creating a semantic representation can be compared to a factor analysis of co-occurrences of individual words. The resulting factor structure can be used to compare how any words, present in the text corpus, are similar to one another. It has been argued that this is a model of how humans learn new words, where we intuitively recall/ infer in which context a new word co-occurs and understand its meaning depending on the context and how rich our own vocabulary is (Landauer et al. 2008). A full explanation on the method can be found elsewhere (Landauer et al. 2008). A less detailed explanation of the procedure behind the creation of a semantic space and the quantification of the freely generated narratives follows next.

The semantic representation or quantification of the generated words was conducted using the web-based software semanticexcel (http://www.semanticexcel.com), which was developed by Sverker Sikström at Lund University for computing and analyzing semantic representations. To create a semantic representation with a high quality, semanticexcel uses what might be the largest possible available text corpus in Swedish, namely, the Swedish version of the Google n-grams database (see the Google n-grams project: http://ngrams.googlelabs.com). Semanticexcel also supports a number of other languages using other versions of Google n-grams databases (e.g., English, Spanish, German, French, Italian, Romanian, Norwegian). An n-gram consists of a very short text consisting of $n$ (typically $n \leq 5$, and in this case we use $n=5$ ) number of words, and the frequency of occurrences of this text sequence in the corpus, for example the 5 -gram "about all that you have" occurs 389 in the database. This database is comprised of a large amount of Terabytes of text data (for recent description of the Google n-gram database see Lin et al. 2012). The semanticexcel software uses a semantic representation generated from a word co-occurrence matrix in which rows consist of the 120,000 and the columns consist of the 10,000 most common words from the Google n-gram database, thus generating a huge matrix consisting of 1,200,000,000 cells. Each cell in the matrix represents the frequency of co-occurrence of the words in the corresponding row and column, so that in the 5-gram exemplified above would, for example, increase the frequency of the cell associated to "about-all", the cell "have-all", etc. with 389. The contexts are generated from Google 5 -gram. See Table 1 for a small-scale example of this co-occurrence matrix containing six single words and two contexts.

A semantic representation of the co-occurrence matrix is generated by factorization conducted using the singular value decomposition (SVD) algorithm. This algorithm compresses the information in the original matrix (Table 1) while maintaining as 
Table 1 Small scale example of the co-occurrence matrix in which each cell represents the co-occurrence frequency of the 5-gram based on 6 single words from 2 contexts: sun is shining outside, sun is warm and yellow

\begin{tabular}{|c|c|c|c|c|c|c|}
\hline & Sun & Is & Shining & Outside & Warm & Yellow \\
\hline Sun & 0 & 2 & 1 & 1 & 1 & 1 \\
\hline Is & 2 & 0 & 1 & 1 & 1 & 1 \\
\hline Shining & 1 & 1 & 0 & 1 & 0 & 0 \\
\hline Outside & 1 & 1 & 1 & 0 & 0 & 0 \\
\hline Warm & 1 & 1 & 0 & 0 & 0 & 1 \\
\hline Yellow & 1 & 1 & 0 & 0 & 1 & 0 \\
\hline
\end{tabular}

In application of latent semantic analysis in computational linguistic, typically highly frequent words that do not contain any semantic information are omitted (e.g., "we" and "in"). However, our focus is to apply latent semantic analysis in personality and social psychology, where for example pronouns carry highly important information. Therefore, we have chosen to keep all these words, although they may to a minor extent influence the quality of the semantic representation for other words negatively

much information as possible (see Landauer 2008). However, prior to the application of SVD, the cells are normalized so that they containing the logarithm of frequency plus 1 $(\log ($ frequency +1$))$, which is necessary to diminish the differences in word frequency between the cells. The results matrix presented in Table 2 represents words as numerical vectors on each row, and semantic dimensions/factors as columns. The dimensions are ordered by how much variances it accounts for in the original matrix (Table 1), so that the first dimension is the most important one. In the semantic representation of the Swedish language we keep the 256 first dimensions that are generated from the SVD. This value is obtained by evaluating the quality of the semantic representation as a function of the number of dimensions, where too few dimensions creates a poor quality because there is insufficient information to represent the semantic dimensions, and too many dimensions yields poor generalization (i.e., over-fitting) of word meaning and also poor quality. The quality of the semantic representation is evaluated by a synonym test.

This analysis is computationally very similar to an ordinary factor analysis, typically conducted in psychological research, where the columns can be interpreted as factor, and a cell the factor loading related to a word. However, some differences between latent semantic analysis and how factor analysis normally is carried out can be noted; in latent semantic analysis the co-occurrence matrix is generated from a context in a text corpora and normalized in a particular way. In factor analysis, researchers are typically interested of the resulting factor loadings of the first few (1-3) factors, whereas in latent semantic analysis the focus of interest are the similarity of word vectors typically consisting of a few hundreds dimension/factors.

Table 2 Semantic representation generated by factorization using singular value decomposition (SVD) of Table 1

\begin{tabular}{lcccccc}
\hline & Dimension 1 & Dimension 2 & Dimension 3 & Dimension 4 & Dimension 5 & Dimension 6 \\
\hline Sun & 0.5561 & 0.7071 & 0.4195 & 0.0000 & -0.1216 & -0.0000 \\
Is & -0.5561 & -0.7071 & 0.4195 & 0.0000 & -0.1216 & -0.0000 \\
Shining & -0.2647 & 0.0000 & -0.4803 & 0.0000 & -0.4463 & -0.7071 \\
Outside & -0.2647 & 0.0000 & -0.4803 & 0.0000 & -0.4463 & 0.7071 \\
Warm & -0.3474 & 0.0000 & -0.3055 & -0.7071 & 0.5348 & 0.0000 \\
Yellow & -0.3474 & 0.0000 & -0.3055 & 0.7071 & 0.5348 & 0.0000 \\
\hline
\end{tabular}


The meaning of individual dimension in the semantic representation is seldom of interest in latent semantic analysis. However, the first dimension typically codes for word frequency (or $\log ($ frequency)), and the second dimension codes for word valence. Higher dimensions can also be interpreted, by looking at communalities of word meaning that loads high to the dimensions, although such interpretations are often difficult to conduct. Nevertheless, by taking the cosine of the angle between the two vectors representing two words, the semantic dimensions can typically be used to estimate the semantic similarity between words. In short, the length of the vectors representing a word is first normalized to a length of one. Following this normalization, the cosine of the angel becomes particular easy to calculate, that is, by simply taking the dot product between the vectors-multiplying each dimension and summing the results. Values close to 1 represent very similar words, values close to 0 represent very dissimilar words, and values close to -1 represents two vectors pointing in the opposite directions.

A semantic representation of a sentence, or an utterance from a participant, can be generated from several words by aggregating the vectors for each word. The resulting vector is then normalized to the length of one (see Landauer et al. 2008). In the present study, the semanticexcel software simply adds the vectors representing each of the words generated by the participants. In other words, each participant's set of narratives obtains a quantified semantic representation based on the sum of the vectors corresponding to each of the participant's words. For example, using the theoretical matrix in Table 2, for a participant who generated the words warm and shining to describe her/his life event, the vectors in which these specific words appear are added-this is of course done for all words the participant generated. In this way, the words generated by the participants are quantified based on the semantic representation of the Google n-grams database. Low frequency words that do not exist in the semantic representation are simply ignored.

Investigating the relationship between narratives and personality This analysis aimed to answer the question whether the quantified meaning (i.e., the semantic representation) of participants' narratives contained information about participants' personality traits scores. Semanticexcel uses multiple linear regressions $(\mathrm{Y}=\mathrm{c} \times \mathrm{X})$, with the semantic representations as input (X, i.e., a participants $\times$ semantic dimensions matrix), to train the regression coefficients (c, i.e., a vector corresponding to the weights of each semantic dimension) to predict each of the personality scales $(\mathrm{Y})$. One multiple linear regression was conducted for each personality trait. A N-leave (where $\mathrm{N}$ is $10 \%$ of the total dataset) out-cross validation procedure is used to evaluate the results from the multiple linear regression so that the-to-be predicted data-point is removed from the training set, where the coefficients of the multiple linear regression are generated, and where these coefficients are applied to make a prediction on the left out test data-point. Thus, 10 (N) new training and testing sets are made for cross-validation. To avoid over-fitting, a subset of the dimensions in a semantic representation is used, where fitting with too many parameters in relation to the number test data-points may yield poor generalization to test data-set. This subset is selected by using the most predictive dimensions in the training set, where the predictive dimensions were selected based on the training dataset prior, and then applied on the test dataset. Furthermore, the maximum number of dimensions used is set to one half of the total number of predicted data points (see Garcia and Sikström 2013). In short, semanticexcel generates the predicted values by 
applying the regression coefficients (c) from the training data set on the test dataset. To evaluate whether participants' personality trait scores are significantly predicted by the semantic representation of the narratives, the personality trait scores are simply correlated with the predicted values. A significant positive correlation (one-tailed) indicates that the semantic representation predicts the outcome variable (i.e., the participants' score in each of the personality traits).

\section{Overview of the narrative-datasets}

We constructed a series of four figures in order to give the reader a sense of what is present in the semantic representation of the narrative of positive and negative life events, one presented here and the others presented as Additional file 1. In short, the Fig. 1 presents a frequency analysis in which we tested if the occurrence of words in the participants' narrative differed from the occurrence of the same words in natural language (i.e., the Google $\mathrm{N}$-gram database). Significant testing was made with $\chi^{2}$ tests, correcting for multiple comparisons using the Bonferroni method. Figure 1, created with http:// www.wordle.net, shows the 506 words in the life narratives that have a relative frequency that is significantly larger than the frequency count in Google n-grams. Two words were omitted from the original set of words: 'Tarkett' and 'Panton'. These two words were names of a company and a dog respectively, thus found to be significant only due to being of uniquely important value for specific individuals in the sample. The font size of the words in the word cloud is proportional to the $Q$-value in the $\chi^{2}$ test. Additional analysis, conducted in the same manner as explained above, were conducted using only narratives of positive (see Additional file 1: Figure S1) or only narratives of negative (see Additional file 1: Figure S2) life events. These results suggest that the conditions generated different narratives, as illustrated by the different words in each condition (Additional file 1: Figures S1, S2). The amalgamation of both conditions (Fig. 1) presents an important image of the uniqueness of adolescents' narratives of live events-namely, feelings and social relationships. We correlated the semantic measure of the positive and negative manipulations with the corresponding empirical value, and the results were significant $(r=0.45, p<0.001)$, suggesting that the conditions generated distinctive narratives, as expected (see additional analyses of cluster of words significantly overrepresented in written narratives of negative and positive life events, Additional file 1: Figure S3). However, the semantic correlate to gender was not significant $(r=0.192$,

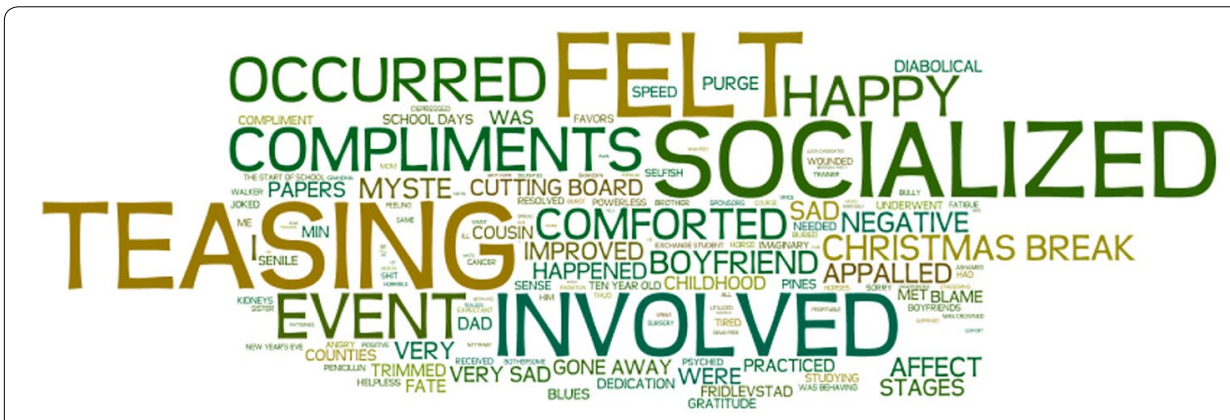

Fig. 1 Participants' $(N=79)$ positive and negative life narratives depicted as a word cloud (created with wordle.net). The words are translated from Swedish to English. The font size is proportional to the Q-value in a $\chi^{2}$ test where the word frequencies of narratives are compared with the word frequencies in Google n-gram 
$p=0.053)$, neither was age $(r=0.11, p=181)$. Moreover, additional analysis (Additional file 1: Figure S4) of cluster of words significantly overrepresented in the written narratives of life events in relation to character, showed that words related to low self-directedness and cooperativeness had a negative tone (e.g., dismayed, helpless, blame), while those related to high levels were mostly verbs; which suggest more active and dynamic narratives (cf. Pennebaker 2011).

\section{Results and discussion}

Table 3 shows the correlations between the personality variables and descriptive statistics. It is noteworthy that there are various correlations between several of the traits both within and between the Big Five and the TCI. Interestingly, self-directedness, cooperativeness, and self-transcendence were significantly correlated to several of the Big Five traits. Furthermore, cooperativeness was significantly positively correlated with both self-directedness and self-transcendence; meanwhile self-transcendence and selfdirectedness were significantly negative correlated. In general, these findings are replications of earlier studies (e.g., De Fruyt et al. 2000b, 2006; Garcia 2012a; Garcia et al. 2013). Among the strongest correlations, between models, is that of persistence-conscientiousness $(r=0.62)$, self-directedness-Neuroticism $(r=-0.61)$, and cooperativeness-agreeableness $(r=0.77)$. An individual high in persistence is industrious, diligent, hard-working, ambitious, perseverant, and perfectionist (Cloninger et al. 1993). These descriptions do apply to an individual scoring high in Conscientiousness (cf. Garcia et al. 2014). An individual high in Self-directedness is mature, responsible, purposeful, resourceful, goal-directed, and accepts her/himself (Cloninger et al. 1993). This is almost the opposite of an individual high in Neuroticism: anxious, angry, hostile, depressive, and self-conscious (cf. Garcia et al. 2014). Finally, an individual high in cooperativeness is tolerant of others, empathic, helpful, compassionate, and principled (Cloninger et al. 1993), which is in line with agreeableness.

At first sight, these correlations indicate that some of the expectations with regard to the relationship between self-directedness-narratives could be expected for neuroticism as well. Nevertheless, most of these relationships are moderate (see Ferguson 2009, who suggest a $r>0.80$ for being considered as strong). In addition, the significant relation between persistence and conscientiousness might actually explain why conscientiousness was not related to agentic themes in the McAdams' study (McAdams et al. 2004). In other words, Conscientiousness is probably more descriptive of an individuals' industrious temperament, rather than her/his responsible character. Moreover, the relatively strong correlations between traits from both models might be due to the small sample used here. The cooperativeness-agreeableness correlation $(r=0.77)$, for example, is actually higher than the one found by others ( $r=0.51$ in De Fruyt et al. 2006). Whatever the case, our findings detailed next are consistent with earlier suggestions: personality traits assessed by these two models are related, but they measure different aspects of personality.

\section{Correlation analysis between psychometric and sematic measures}

The results generated from the semantic representation were correlated (one-tailed) with their respective empirical personality score. The analysis based on the semantic representations of the narratives showed that, as partially expected, only two personality 
traits were related to the semantic representations of the described life events. Specifically, self-directedness $(r=0.31, p=0.005)$ and cooperativeness $(r=0.34, p=0.002)$ correlated with the semantic representation based on the narratives generated by the pupils (See Table 4). A post hoc power analysis for these simple correlations yielded a Power of 0.70 and 0.90 , respectively, suggesting a chance type II error between 0.30 and 0.10 . Repeating these analysis, using gender and age as covariates, did not influence the results significantly. Conducting these analyses separately for the positive and negative conditions, however, showed significant effects in the positive condition for cooperativeness $(r=0.38, p=0.009)$ and self-transcendence $(r=0.37, p=0.012)$, but not in the negative condition. A post hoc power analysis for these simple correlations yielded a Power of 0.60, suggesting a chance type II error of 0.40.

Together with the correlation findings between personality traits from both models, this finding suggests that both models measure related traits but that these traits are distinctively related to adolescents' interpretations of life events. The TCI, for instance, has earlier showed predictive validity as good or better when compared to 11 modern multi-scale personality inventories by independent investigators (Grucza and Goldberg 2007). Hence, our findings support the validity of the TCI in predicting actual behavior and also that the TCI is a valid tool for the investigation of how individuals interpret and describe events in their lives (see Luhmann et al. 2014, who suggested that Big Five traits do not have a major impact on how individuals interpret events in their lives).

The results regarding the separate conditions (i.e., positive life events and negative life events) suggest that character is here associated to narratives of positive life events and not narratives of negative life events. There is indeed research on life events suggesting that explanations (e.g., explanatory style) of positive and negative life events are only weakly correlated (Miller and Ross 1975), probably because individuals use self-serving bias more extensively when they explain positive life events (Miller and Ross 1975). Hence, this explains why character was only associated to narratives of positive life events; character is after all the individual's concept of the self. Nevertheless, how people explain positive events has been found to not be a strong predictor of depression (Seligman et al. 1979). In other words, this suggests that our findings with regard to the relation between narratives of positive events and character traits are trivial. We argue that they are important because the low correlation between explanations of positive and negative life events (see Miller and Ross 1975) points to a high variance in explanations for positive life events, even among individuals with pessimistic explanations for negative events (Abramson and Needles 1990). In addition, positive life events are associated to life satisfaction and positive emotions (Garcia 2011); thus, character traits associated to adolescents' narratives are of importance for understanding their well-being as well. The lack positivity in life, for example, is more predictive of subsequent mortality and morbidity than the presence of negative emotions (Huppert and Whittington 2008).

More importantly, the relationship between adolescents' agentic traits and narratives of their life events is in line with research suggesting that during this period of life, adolescents narratives and conversations about recent life events are filled with issues about autonomy (Weeks and Pasupathi 2010). On the other hand, the finding showing that cooperativeness is associated to the written narratives of life events might only mirror that the narratives were written 3 months after pupils' Christmas break, a time usually 


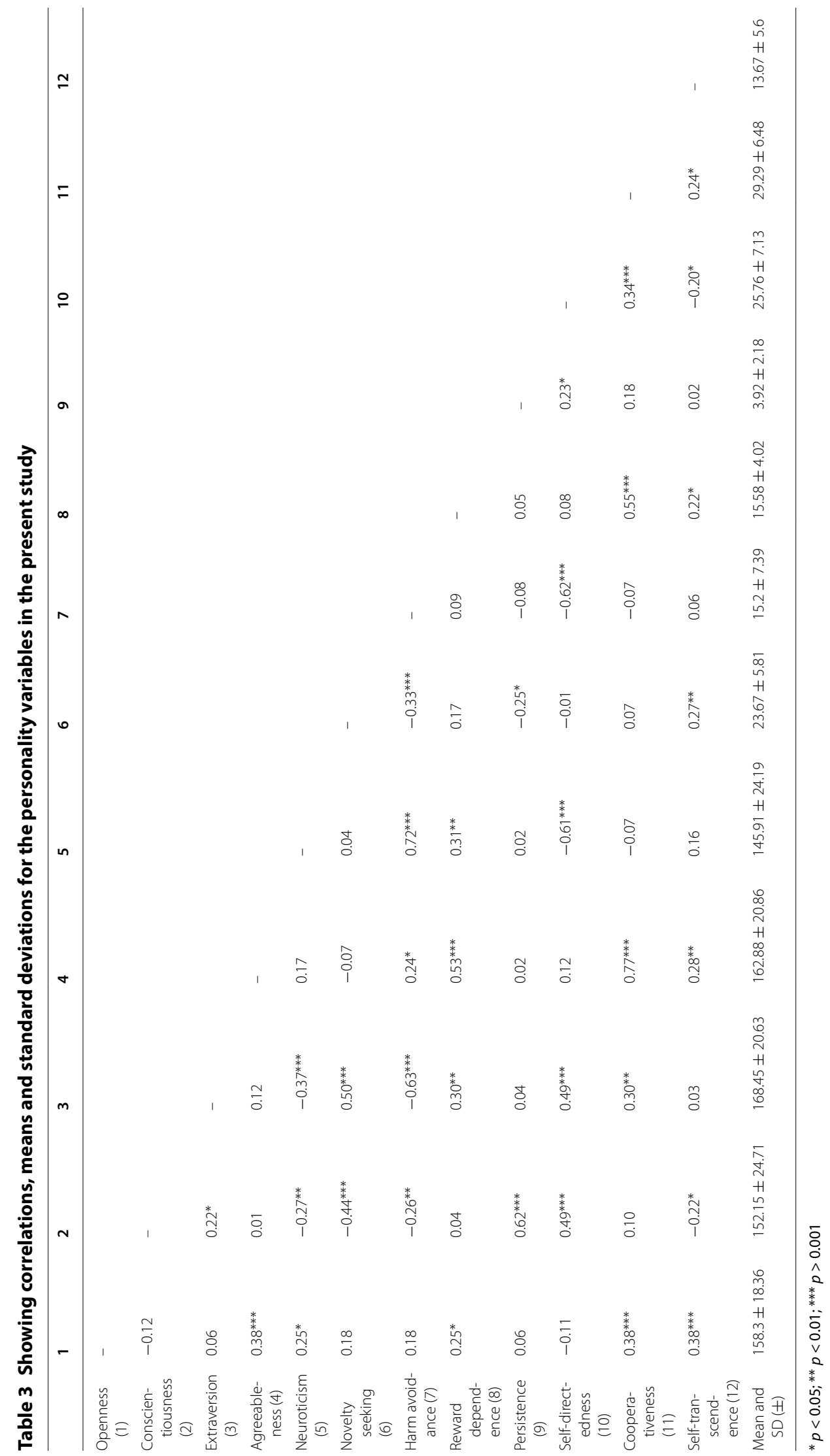


Table 4 Showing the correlation between age, gender, self-reported personality and the corresponding values related to the semantic representation of the description of life events

\begin{tabular}{lcc}
\hline & Semantic representation & \\
\cline { 2 - 3 } & $\boldsymbol{r}$ & $\boldsymbol{p}$ \\
\hline Demographics & & \\
Gender & 0.192 & 0.053 \\
Age & 0.110 & 0.181 \\
Big Five & & \\
Openness & 0.091 & 0.240 \\
Conscientiousness & -0.029 & 0.591 \\
Extraversion & 0.054 & 0.337 \\
Agreeableness & -0.161 & 0.896 \\
Neuroticism & 0.028 & 0.415 \\
Temperament and character & & \\
Novelty seeking & 0.011 & 0.466 \\
Harm avoidance & 0.040 & 0.371 \\
Reward dependence & -0.103 & 0.801 \\
Persistence & 0.022 & 0.429 \\
Self-directedness & 0.311 & 0.005 \\
Cooperativeness & 0.339 & 0.002 \\
Self-transcendence & 0.015 & 0.451 \\
\hline Significant correlations are printed in italics & &
\end{tabular}

spend among family and friends - the exact time span given for the recollection of the life events. Nevertheless, agreeableness was not associated to the narratives, thus, suggesting that cooperativeness might catch communal themes in the narratives better that agreeableness does. Both cooperativeness and agreeableness have earlier, as well as in the present study, been found to be positively related (De Fruyt et al. 2006; Garcia 2011) to Reward Dependence or the tendency of being sentimental, warm, attached, and dependent (Cloninger et al. 1993). In contrast to cooperativeness, however, agreeableness was here positively related to Harm Avoidance or the tendency of being worrying, pessimistic, fearful, and shy (Cloninger et al. 1993). That is, the associations between agreeableness and temperament traits are different in the present sample than as it could be expected, which might explain the results. Nevertheless, more data is needed in order to interpret if differences in the relationships between traits are behind different associations between traits and narratives. Moreover, Magen's (1998) research suggests that adolescents address simple forms of self-transcendence-usually not referring to a macrocosmic unity. This explains why this character trait was not associated to the amalgamated semantic representation of the life events. Nonetheless, some adolescents can express transcendent feelings (e.g., mystical identification with a crowd on a strike in the streets) and even adolescents' homelier joys uncover "those universals that lead from and go beyond personal experience" (Magen 1998, pp. 167). This observation is mirrored in the present study as well; adolescents' narratives of positive events were indeed related to their transcendental tendencies. 


\section{Word analysis in relation to personality traits}

Following previous micro-level research suggesting that the usage of pronouns in narratives mirror individuals' inner thoughts and personality (Campbell and Pennebaker 2003), we investigated whether the pronoun's rate frequency in the narratives of life events correlated with the three character traits that were significantly associated to the narratives. Cooperativeness correlated negatively with 'me' and self-transcendence negatively with 'mine'. Suggesting that the lower individuals scored in cooperativeness and self-transcendence, the more self-focused their narrative was. Indeed, frequent use of first person pronouns is a common characteristic of depressed individuals (Pennebaker 2011). In this line, low levels of self-directedness, cooperativeness and self-transcendence are predictive of ill-health (e.g., Cloninger and Zohar 2011) and dysfunction and suffering in different aspects of life, such as, school and home (Garcia et al. 2013a). In other words, a healthy personality is characterized by an outlook of unity or connectedness, rather than by an outlook of separateness (Cloninger 2013). This outlook of separateness is clearly depicted in the present study by adolescents more frequent use of 'me' and 'mine' in conjunction with low tolerance towards others, less helpfulness, less sense of meaning (i.e., low cooperativeness and self-transcendence). The lack of self-transcendence in adolescence is, for example, suggested to mirror that adolescents pursue of positive emotions tend to be egocentric and directed by their own desires, which in turn is contradictory to the willingness to become dedicated to the well-being of others or pro-social causes that transcend the self (Magen 1996). Nevertheless, our results do not suggest that frequent use of plural pronouns may provide an objective indicator of a healthy outlook of connectedness in adolescent identity formation. It is, however, probable that pronouns such as we might represent more mature versions of pronouns such as I (D. M. Svrakic, personal communication, April 4, 2014).

\section{Limitations, strengths, and future research}

The present study had a rather small number of participants and we did not control for ethnicity or linguistic skills. Nevertheless, as far as we know by asking teachers at the school, all adolescents were Swedish and none of them had writing or reading disabilities. It is plausible, yet, to suggest that by using a larger text corpus of narratives, other traits might show significant relations. Thus, our findings need to be interpreted with caution. Moreover, we assigned some adolescents to write about positive events and others about negative events to avoid having the recollections influencing the descriptions. The conditions, however, were not used in this study as an experimental design. Future studies may investigate if the order in which events are retrieved has any effect on the link between personality-narrative. In addition, future longitudinal studies might help to affirm causal relations between variables.

Although previous findings have shown that heritability influences on character are about the same across studies using different age groups, there are some differences worth noting. For example, while the character scales do not show common environmental influences in research among older adults (e.g., Gillespie et al. 2003), a small common environmental influence for self-directedness and cooperativeness has been found among young adults (20-30 years of age; e.g., Ando et al. 2004). In addition, recent research using one of the largest population-based-twin-studies among adolescents, 
found suggestive evidence of common environmental influence for all of the character scales (Garcia et al. 2013b; Mousavi et al. 2015). In sum, the genetic structure of character scales in the adolescent sample shows a modest but noteworthy proportion of shared environmental influence that is not present in adult samples. This suggest a "shift" in type of environmental influence (i.e., shared to non-shared) from adolescence to adulthood with regard to character (Lester et al. 2015). Thus, it is plausible that the results might not be replicated in samples using other age cohorts. Nevertheless, recent prospective studies show increases in self-directedness and cooperativeness with age (from 20 to 45 years, Josefsson et al. 2013). Hence, we suggest that the relationship between character traits and narratives of past events should be present even among adults.

\section{Clinical implications}

There is a well-established line of research suggesting that personality is associated to adolescents' well-being (e.g., Cloninger and Zohar 2011; Garcia 2011, 2012a; Nima et al. 2012, 2013a; Garcia et al. 2013a, c; Schütz et al. 2013a; Magen 1996). From that point of view, there might be important implications based on the findings presented here. However, this is a cross-sectional study and as such, it cannot suggest that changes in one variable (e.g., personality) might influence the other (e.g., the way adolescents describe a life event). That being said, the study of expressing emotions through written words demonstrates that putting emotionally upsetting experiences into words can influence thoughts, feelings, and even physical health (Pennebaker 1997, 2011). Individuals who change perspectives (e.g., writing about their own feelings and then write about other people's feelings) when writing about an emotional upsetting life event for 15-20 min for 5 consecutive days are the ones who benefit the most from emotional writing (Pennebaker 2011; Campbell and Pennebaker 2003). Thus, a person's life story can be "edited" by fairly simple means, such as taking other peoples' perspective when writing (see Wilson 2011). Together with the present findings, interventions targeting development of taking other peoples perspectives, one feature of cooperativeness, might lead to changes in the way individuals describe their life, at the end influencing their well-being (see also Johansson et al. 2013, who showed that increases in agency and cooperation are associated to improvements in depression). Nevertheless, it has been suggested that the genetic and factor structure of character traits implies that something quite different should be tried if one aspires to change them much (Lester et al. 2015). Indeed, well-being interventions recently developed (e.g., well-being coaching; http:// anthropedia.org/learn-more/) require the development of self-awareness and personality of the whole human being (i.e., body, mind and soul).

"Your life is not the one you lived,

but the one you remember

and how you remember it to tell it"

Gabriel Garcia Marquez.

"Me, We"

Muhammad Ali at Harvard University, 1975. 


\section{Additional file}

Additional file 1: Table S1. Reliability analysis on the TCI traits with regard to age. Figure S1 and S2. Word frequency analyses to test if the occurrence of words in the positive and negative life events narratives, respectively, differed from the occurrence of the same words in natural language (i.e., the Google N-gram database). Figure $\mathbf{S 3}$. Analyses of cluster of words significantly overrepresented in written narratives of negative and positive life events. Figure S4. Analyses of cluster of words significantly overrepresented in the amalgamated life events narratives in relation to self-directedness and cooperativeness (i.e., the only two character traits associated to the amalgamated narratives).

\section{Authors' contributions}

DG took a leading role in the writing of the paper and defining the research questions. SS analysed the data. SS, HA, OK, $\mathrm{PR}, \mathrm{TA}$, and CRC made significant contributions in writing and conceptual development of the manuscript. All authors read and approved the final manuscript.

\section{Author details}

${ }^{1}$ Network for Empowerment and Well-Being, Gothenburg and Lund, Sweden. ${ }^{2}$ Blekinge Centre of Competence, Karlskrona, Sweden. ${ }^{3}$ Center for Well-Being, Washington University School of Medicine in St. Louis, St. Louis, MO, USA. ${ }^{4}$ Centre for Ethics, Law and Mental Health (CELAM), University of Gothenburg, Gothenburg, Sweden. ${ }^{5}$ Department of Psychology, Lund University, Lund, Sweden. ${ }^{6}$ Department of Psychology, University of Gothenburg, Gothenburg, Sweden.

\section{Acknowledgements}

We would like to thank Malin Tiara Norlin for her help with the Figures. Our gratitude is also directed to the adolescents who offered their important time to participate in the study. Last but not the least, we would like to thank Doctor Dragan M. Svrakic for his most asserted comment on the pronoun WE being a more mature version of the pronoun I.

\section{Funding}

This study was supported by Stiftelsen Kempe-Carlgrenska Fonden, AFA Insurance (Dnr. 130345), and a grant from the Swedish Research Council on "Semantic spaces as a method in psychology". The funders had no role in study design, data collection and analysis, decision to publish, or preparation of the manuscript.

\section{Compliance with ethical guidelines}

\section{Competing interests}

The authors declare that they have no competing interests.

Received: 30 January 2015 Accepted: 17 August 2015

Published online: 08 September 2015

\section{References}

Abramson, L., \& Needles, D. J. (1990). Positive life events, attributional style, and hopefulness: testing a model of recovery from depression. Journal of Abnormal Psychology, 99, 156-165.

Ando, J., Suzuki, A., Yamagata, S., Kijima, N., Maekawa, H., Ono, Y., \& Jang, K. L. (2004). Genetic and environmental structure of Cloninger's temperament and character dimensions. Journal of Personality Disorders, 18, 379-393. doi:10.1521/ pedi.18.4.379.40345.

Arvidsson, D., Sikström, S., \& Werbart, A. (2011). Changes in self- and object-representations following psychotherapy measured by a theory-free, computational, semantic space method. Psychotherapy Research, 21, 430-446. doi:10.108 0/10503307.2011.577824.

Borg, J., Andrée, B., Soderstrom, H., \& Farde, L. (2003). The serotonin system and spiritual experiences. American Journal of Psychiatry, 160, 1965-1969.

Brändström, S., Schlette, P., Przybeck, T. R., Lundberg, M., Forsgren, T., Sigvardsson, S., et al. (1998). Swedish normative data on personality using the temperament and character inventory. Comprehensive Psychiatry, 39, 122-128.

Brändström, S., Sigvardsson, S., Nylander, P.-O., \& Richter, J. (2008). The Swedish Version of the temperament and character inventory (TCI). A cross-validation of age and gender influences. European Journal of Psychological Assessment, 24, $14-21$.

Campbell, R. S., \& Pennebaker, J. W. (2003). The secret life of pronouns: flexibility in writing style and physical health. Psychological Science, 14, 60-65.

Chung, C., \& Pennebaker, J. (2007). The psychological functions of function words. In K. Fiedler (Ed.), Social communication (pp. 343-359). New York: Psychology Press.

Cloninger, C. R. (2004). Feeling good: the science of well-being. New York: Oxford University Press.

Cloninger, C. R. (2006). Fostering spirituality and well-being in clinical practice. Psychiatric Annals, 36, 1-6.

Cloninger, C. R. (2013). What makes people healthy, happy, and fulfilled in the face of current world challenges. Mens Sana Monographs, 11, 16-24

Cloninger, C. R., \& Garcia, D. (2015). The heritability and development of positive affect and emotionality. In M. Pluess (Ed.), Genetics of psychological well-being - the role of heritability and genetics in positive psychology (pp. 97-113). New York: Oxford University Press. 
Cloninger, C. R., Svrakic, D. M., \& Przybeck, T. R. (1993). A Psychobiological model of temperament and character. Archives of General Psychiatry, 50, 975-989.

Cloninger, C. R., \& Zohar, A. H. (2011). Personality and the perception of health and happiness. Journal of Affective Disorders, 128, 24-32.

Cohler, B. J. (1982). Personal narrative and life course. Life-Span Development and Behavior, 4, 205-241.

Costa, P.T. Jr., \& McCrae, R. R. (1992). Revised NEO personality inventory (NEO PI-R) and NEO five-factor inventory (NEO-FFI) professional manual. Odessa: Psychological assessment resources. Swedish version: NEO PI-R (2003), Stockholm: Psykologiförlaget $\mathrm{AB}$.

Daiute, C. (2010). Critical narrating by adolescents growing up in war: case study across the former Yugoslavia. In K. C. McLean \& M. Pasupathi (Eds.), Narrative development in adolescence, advancing responsible adolescent development. New York: Springer. doi:10.1007/978-0-387-89825-4_4.

De Fruyt, F., Mervielde, I., Hoekstra, H. A., \& Rolland, J. P. (2000a). Assessing adolescents' personality with the NEO-PI- R. Assessment, 7, 329-345.

De Fruyt, F., Van De Wiele, L., \& Van Heeringen, C. (2000b). Cloninger's psychobiological model of temperament and the five-factor model of personality. Personality and Individual Difference, 29, 441-452.

De Fruyt, F., Van De Wiele, L., \& Van Heeringen, C. (2006). The validity of Cloninger's psychobiological model versus the five-factor model to predict DSM-IV personality disorders in a heterogeneous psychiatric sample: facet and residualized facet descriptions. Journal of Personality, 74, 479-510.

De la Rie, S. M., Duijsens, I. J., \& Cloninger, C. R. (1998). Temperament, character, and personality disorders. Journal of Personality Disorders, 12, 362-372.

Dunlop, W. L., \& Tracy, J. L. (2013). Sobering stories: narratives of self-redemption predict behavioral change and improved health among recovering alcoholics. Journal of Personality and Social Psychology, 104, 576-590.

Erikson, E. H. (1968). Identity: youth and crisis. New York: Norton.

Ferguson, C. J. (2009). An effect size primer: a guide for clinicians and researchers. Professional Psychology, Research and Practice, 40, 532-538.

Garcia, D. (2011). Two models of personality and well-being among adolescents. Personality and Individual Differences, 50, 1208-1212. doi:10.1016/j.paid.2011.02.009.

Garcia, D. (2012a). The affective temperaments: differences between adolescents in the big five model and Cloninger's psychobiological model of personality. Journal of Happiness Studies, 13, 999-1017. doi:10.1007/s10902-011-9303-5.

Garcia, D. (2012b). The affect, intentionality, effort \& adaptation to a life event measure. International Journal of Psychology, $475,620$.

Garcia, D., Anckarsäter, H., \& Lundström, S. (2013a). Self-directedness and cooperativeness, psychosocial dysfunction and suffering in ESSENCE. The Scientific World Journal,. doi:10.1155/2013/416981.

Garcia, D., Lundström, S., Brändström, S., Råstam, M., Cloninger, C. R., Kerekes, N., et al. (2013b). Temperament and character in the child and adolescent twin study in Sweden (CATSS): comparison to the general population, and genetic structure analysis. PLoS One, 8(8), e70475. doi:10.1371/journal.pone.0070475.

Garcia, D., Nima, A. A., \& Archer, T. (2013c). International note: temperament and character's relationship to subjective well-being in Salvadorian adolescents and young adults. Journal of Adolescence, 36, 1115-1119. doi:10.1016/j. adolescence.2013.08.018.

Garcia, D., Kjell, O. N. E., \& Sikström, S. (2015). A collective picture of what makes people happy: words representing social relationships, not money or material things, are recurrent with the word 'Happiness' in online newspapers. In G. Riva, B. K. Wiederhold, \& P. Cipresso (Eds.), The psychology of social networking. Personal experience in online community (Vol. 1). Warsaw: DeGruyter Open.

Garcia, D., Nima, A. A., Rappe, C., Rapp Ricciardi, M., \& Archer, T. (2014). The relationship between the JobMatchTalent Test and the NEO PI-R: construct validation of an instrument designed for recruitment of personnel. PLoS One, 9(3), e90309. doi:10.1371/journal.pone.0090309.

Garcia, D., \& Sikström, S. (2013). Quantifying the semantic representations in adolescents' memories of positive and negative life events. Journal of Happiness Studies, 14, 1309-1323. doi:10.1007/s10902-012-9385-8.

Garcia, D., \& Sikström, S. (2014). The dark side of facebook—dark triad of personality predicts semantic representation of status updates. Personality and Individual Differences, 67, 92-94. doi:10.1016/j.paid.2013.10.001.

Gazzaniga, M. S. (2011). Who's in charge? Free will and the science of the brain. New York: HarperCollins Publishers.

Gillespie, N. A., Cloninger, C. R., Heath, A. C., \& Martin, N. G. (2003). The genetic and environmental relationship between Cloninger's dimensions of temperament and character. Personality and Individual Differences, 35, 1931-1946.

Grucza, R. A., \& Goldberg, L. R. (2007). The comparative validity of 11 modern personality inventories: predictions of behavioral acts informant reports and clinical indicators. Journal of Personality Assessment, 89, 167-187.

Gustafsson Sendén, M., Lindholm, T., \& Sikstrom, S. (2014a). Biases in news media as reflected by personal pronouns in evaluative con- texts. Social Psychology, 45, 103-111.

Gustafsson Sendén, M., Lindholm, T., \& Sikstrom, S. (2014b). Selection bias in choice of words: evaluations of "I" and "We" differ between contexts, but "They" are always worse. Journal of Language and Social Psychology, 33, 49-67. doi:10.11 77/0261927X13495856.

Gustafsson Sendén, M., Sikström, S., \& Lindholm, T. (2015). "She" and "He" in news media messages: pronoun use reflects gender biases in semantic contexts. Sex Roles, 72, 40-49. doi:10.1007/s11199-014-0437-x.

Gutierrez, F., \& Torrens, M. (2001). Psychometric properties of temperament and character inventory questionnaire in Spanish psychiatric population. Acta Psychiatrica Scandinavica, 103, 143-147.

Haidt, J. (2006). The happiness hypothesis: finding modern truth in ancient wisdom. New York: Basic Books.

Huppert, F. A., \& Whittington, J. E. (2008). Evidence for the independence of positive and negative well-being: implications for quality of life assessment. British Journal of Health Psychology, 8, 107-122.

Johansson, R., Lyssarides, C., Andersson, G., \& Rousseau, A. (2013). Personality change after interner-delivered cognitive behavior therapy for depression. PeerJ, 1, e39. doi:10.7717/peerj.39.

Josefsson, K., Jokela, M., Cloninger, C. R., Hintsanen, M., Salo, J., Hintsa, T., et al. (2013). Maturity and change in personality: developmental trends of temperament and character in adulthood. Development and Psychopathology, 25, 713-727. 
Kijima, N., Tanaka, E., \& Suzuki, N. (2000). Reliability and validity of Japanese version of the temperament and character inventory. Psychological Reports, 86, 1050-1058.

Köse, S., Sayar, K., Ak, l., Aydin, N., Kalelioğ lu, Ü., Kirpinar, I., et al. (2002). Turkish version of the temperament and character inventory (TCI): reliability, validity, and factorial structure. Bulletin of Clinical Psychopharmacology, 14, 107-131.

Landauer, T. K. (2008). LSA as a theory of meaning. In T. K. Landauer, D. S. McNamara, S. Dennis, \& W. Kintsch (Eds.), Handbook of latent semantic analysis. Mahwah: Lawrence Erlbaum Associates.

Landauer, T. K., \& Dumais, S. (1997). A solution to Plato's problem: the latent semantic analysis theory of acquisition, induction, and representation of knowledge. Psychological Review, 104, 211-240.

Landauer, T. K., McNamara, D. S., Dennis, S., \& Kintsch, W. (2008). Handbook of latent semantic analysis. Mahwah: Lawrence Erlbaum Associates.

Lester, N., Garcia, D., Lundström, S., Brändström, S., Råstam, M., Kerekes, N., Nilsson, T., Cloninger, C. R., Anckarsäter, H. (2015). The genetic structure of the character Su-scales of the temperament and character inventory in adolescence (Manuscript under Editorial Evaluation).

Lilgendahl, J. P., \& McAdams, D. P. (2011). Constructing stories of self-growth: how individual differences in pattersn of autobiographical reasoning relate to well-being in midlife. Journal of Personality, 79, 391-428. doi:10.1111/j.1467-6494.2010.00688.x.

Lin, Y., Michel, J.-B., Lieberman Aiden, E., Orwant, J., Brockman, W., \& Petrov, S. (2012). Syntactic annotations for the Google books Ngram corpus. In Proceedings of the 50th Annual Meeting of the Association for Computational Linguistics, 8-14 July, Jeju, Republic of Korea (pp. 169-174).

Lodi-Smith, J., Geise, A. C., Roberts, B. W., \& Robins, R. W. (2009). Narrating personality change. Journal of Personality and Social Psychology, 2009(96), 679-689. doi:10.1037/a0014611.

Luhmann, M., Hawkley, L. C., \& Cacioppo, J. T. (2014). Thinking about one's subjective well-being: average trends and individual difference. Journal of Happiness Studies, 15(4), 757-781. doi:10.1007/s10902-013-9448-5.

Magen, Z. (1996). Commitment beyond self and adolescence: the issue of happiness. Social Indicators Research, 37, $235-267$.

Magen, Z. (1998). Exploring adolescent happiness. Commitment, purpose and fulfillment. London: Sage Publications Inc.

McAdams, D. P. (1993). The stories we live by. New York: Harper Collins.

McAdams, D. P. (2001). The psychology of life stories. Review of General Psychology, 5, 100-122.

McAdams, D. P., Anyidoho, N. A., Brown, C., Huang, Y. T., Kaplan, B., \& Machado, M. A. (2004). Traits and stories: links between dispositional and narrative features of personality. Journal of Personality, 72, 761-784.

McCullough, G., Huebner, E. S., \& Laughlin, J. M. (2000). Life events, self-concept, and adolescents' positive subjective wellbeing. Psychology in the Schools, 37, 281-290.

McLean, K. C., \& Fournier, M. (2008). The content and processes of autobiographical reasoning in narrative identity. Journal of Research in Personality, 42, 527-545.

McLean, K. C., Pasupathi, M., \& Pals, J. L. (2007). Selves creating stories creating selves: a process model of narrative self development in adolescence and adulthood. Personality and Social Psychology Review, 11, 262-278.

Miller, D. T., \& Ross, M. (1975). Self-serving biases in the attribution of causality: fact or fiction? Psychological Bulletin, 82, 213-225.

Moreira, P. A., Oliveira, J.T., Cloninger, K. M., Azevedo, C., Souza, A., Castro, J., \& Cloninger, C. R. (2012). The psychometrics and validity of the junior temperament and character inventory in Portuguese adolescents. Comprehensive Psychiatry, 53, 1227-1236.

Mousavi, F., Rozsa, S., Nilsson, T., Archer, T., Anckarsäter, H., \& Garcia, D. (2015). Personality and intelligence: persistence, not self-directedness, cooperativeness or self-transcendence, is related to twins' cognitive abilities. PeerJ 3:e1195. doi:10.7717/peerj.1195

Nima, A. A., Archer, T., \& Garcia, D. (2012). Adolescents' happiness-increasing strategies, temperament, and character: mediation models on subjective well-being. Health, 4, 802-810. doi:10.4236/health.2012.410124.

Nima, A. A., Archer, T., \& Garcia, D. (2013a). The happiness-increasing strategies scales in a sample of Swedish adolescents. International Journal of Happiness and Development, 1, 196-211.

Nima, A. A., Rosenberg, P., Archer, T., \& Garcia, D. (2013b). Anxiety, affect, self-esteem, and stress: mediation and moderation effects on depression. PLoS One,. doi:10.1371/journal.pone.0073265.

Nima, A. A., \& Garcia, D. (2015). Factor Structure of the Happiness-Increasing Strategies Scales (H-ISS): activities and coping strategies in relation to positive and negative affect. PeerJ, 3, e1059. doi:10.7717/peerj.1059.

Pasupathi, M., Mansour, E., \& Brubaker, J. R. (2007). Developing a life story: constructing relations between self and experiences in autobiographical narratives. Human Development, 50, 85-110.

Pennebaker, J. W. (1997). Opening Up. The healing power of expressing emotions. New York: Guildford Press.

Pennebaker, J. W. (2011). The secret life of pronouns. What our words say about us. New York: Bloomsbury Press.

Pennebaker, J. W., Francis, M. E., \& Booth, R. J. (2001). Linguistic inquiry and word count (LIWC): LIWC2001. Mahwah: Lawrence Erlbaum.

Pennebaker, J. W., \& King, L. A. (1999). Linguistic styles: language use as an individual differences. Journal of Personality and Social Psychology, 77, 1296-1312.

Rosenberg, P., Sikström, S., \& Garcia, D. (2013). The difference between living biblically and just imagining it: A study on experiential-based learning among Swedish adolescents. School Psychology International, 34, 565-571. doi:10.1177/0143034312471468.

Sandelowski, M. (1991). Telling stories: narrative approaches in qualitative research. Journal of Nursing Scholarship, 23, $161-166$.

Schütz, E., Archer, T., \& Garcia, D. (2013a). Character profiles and adolescents'self-reported happiness. Personality and Individual Differences, 54, 841-844. doi:10.1016/j.paid.2012.12.020.

Schütz, E., Sailer, U., Nima, A., Rosenberg, P., Andersson Arntén, A.-C.., Archer, T., \& Garcia, D. (2013b). The affective profiles in the USA: happiness, depression, life satisfaction, and happiness- increasing strategies. PeerJ, 1, e156. doi:10.7717/ peerj.156. 
Scollon, C. N., Howard, A. H., Caldwell, A. E., \& Ito, S. (2009). The role of ideal affect in the experience and memory of emotions. Journal of Happiness Studies, 10, 257-269.

Seligman, M. E. P., Abramson, L., Semmel, A., \& Von Baeyer, C. (1979). Depressive attributional style. Journal of Abnormal Psychology, 88, 242-247.

Shweder, R. A., Much, N. C., Mahapatra, M., \& Park, L. (1997). The 'Big Three' of morality (autonomy, community, divinity) and the 'Big Three' explanations of suffering. In M. Brandt \& P. Rozin (Eds.), Morality and health (pp. 119-172). New York: Routledge.

Suh, E., Diener, E., \& Fujita, F. (1996). Events and subjective well-being: only recent events matter. Journal of Personality and Social Psychology, 70, 1091-1102.

Thorne, A., Korobov, N., \& Morgan, E. M. (2006). Channeling identity: a study of storytelling in conversations between introverted and extraverted friends. Journal of Personality Research, 41, 1008-1031.

Weeks, T. L., \& Pasupathi, M. (2010). Autonomy, identity, and narrative construction with parents and friends. In K. C. McLean \& M. Pasupathi (Eds.), Narrative development in adolescence, advancing responsible adolescent development. New York: Springer. doi:10.1007/978-0-387-89825-4_4.

Wilson, D. T. (2011). Redirect-the surprising new science of psychological change. New York: Little Brown.

Wray-Lake, L., Maggs, J. L., Johnston, L. D., Bachman, J. G., O'Malley, P. M., \& Schulenberg, J. E. (2012). Associations between community attachments and adolescent substance use in nationally representative samples. Journal of Adolescent Health, 51, 325-331.

Yamasue, H., Abe, O., Suga, M., Yamada, H., Inoue, H., Tochigi, M., et al. (2008). Gender-common and -specific neuroanatomical basis of human anxiety-related personality traits. Cerebral Cortex, 18, 42-46.

\section{Submit your manuscript to a SpringerOpen ${ }^{\circ}$ journal and benefit from:}

- Convenient online submission

- Rigorous peer review

- Immediate publication on acceptance

- Open access: articles freely available online

- High visibility within the field

- Retaining the copyright to your article

Submit your next manuscript at $\mathbf{s p r i n g e r o p e n . c o m ~}$ 